\title{
Las Soledades de Luis de Góngora en el manuscrito 2056 de la Biblioteca de Catalunya: estudio bibliográfico y nuevas variantes de autor*
}

Luis de Góngora's Soledades and the manuscript 2056 from the Biblioteca de Catalunya: bibliographic study and new authorial variants

ANTONIO Rojas CASTRO

Cologne Center for eHumanities

RECIBIDO: 16 DE ABRIL DE 2016

Universität zu Köln

Albertus-Magnus-Platz. Köln

50923 Alemania

arojasca@uni-koeln.de

Orcid ID 0000-0002-8916-4997

Resumen: Desde inicios del siglo XX el interés por

2056 de la Biblioteca de Catalunya desde un punto la génesis de las Soledades ha ido aparejado con la preparación de nuevas ediciones del texto gongorino. Gracias a los pioneros trabajos de Dámaso Alonso se supo que el texto de la Soledad primera que se divulgó en 1613 entre unos pocos allegados de Góngora no era idéntico al texto que don Antonio Chacón y Ponce de León recogió en 1628 en su tributo al conde-duque de Olivares. Tras reseñar el proceso creativo de las Soledades a la luz de los manuscritos y ediciones modernas, con este artículo de vista bibliográfico; en segundo lugar, analizar la copia de las Soledades transmitida en este manuscrito con especial atención a las intervenciones del copista y a las relaciones que se pueden establecer con otros manuscritos tempranos; por último, dar a conocer seis pasajes con variantes de autor inéditas de la Soledad segunda.

Palabras clave: Crítica textual. Luis de Góngora. Reescritura. Soledades. Variantes de autor. se pretende, en primer lugar, describir el manuscrito

* Este trabajo ha sido realizado gracias a una beca de Formación de Personal Investigador (BES2011-045275) financiada por el Ministerio de Economía y Competitividad del gobierno español y concedida a través del proyecto Todo Góngora II (I+D+I FFI2010-17349). Agradezco a las doctoras Mercedes Blanco y María Morrás, así como a los dos revisores anónimos, la lectura y los comentarios enviados, que, sin duda, me han ayudado a mejorar el artículo. 
Abstract: Since the beginning of the twentieth century the interest in the genesis of the Solitudes has been accompanied by the preparation of new editions of the text. Thanks to Dámaso Alonso's pioneering work it was known that the First Solitude was disseminated in 1613 among a few friends of Góngora; it was, however, not identical to the text that don Antonio Chacón y Ponce de Leon offered to the Count Duke of Olivares in 1628. After reviewing the genetic process of the Solitudes in the light of modern editions and manuscripts, this article aims, first, to describe the manuscript 2056 of the National Library of Catalonia from a bibliographic view; second, to analyze the copy of the Solitudes transmitted in this manuscript with a focus on scribal interventions and the relationships that can be established with other early manuscripts; and finally, to present six authorial variants of the Second Solitude that are heretofore unknown.

Keywords: Authorial Variant. Luis de Góngora. Rewriting. Solitudes. Textual Criticism.

\section{INTRODUCCIÓN}

no de los pocos hechos que conocemos con certeza sobre el proceso creativo de las Soledades es que el 11 de mayo de 1613 Luis de Góngora envió desde Córdoba y por mediación de Pedro de Cárdenas una carta al humanista Pedro de Valencia, que residía en Madrid, pidiéndole consejo sobre sus recientes creaciones: la Fábula de Polifemo y Galatea y lo que tenía escrito de las Soledades. Si bien tradicionalmente se ha aceptado que el Polifemo fue escrito durante la primera mitad de 1612, la fecha de redacción de la Soledad primera resulta menos segura; aunque no hay pruebas inequívocas al respecto, en la actualidad se cree que la escritura de la primera parte de las Soledades debió de iniciarse en el otoño de 1612 y prolongarse durante los primeros meses de 1613. En cuanto a la fecha de difusión de esta parte, Dámaso Alonso (Góngora 1936, 316) afirmó que se podía tomar la fecha asignada en el manuscrito Chacón (es decir, 1614) como el momento en que la versión casi definitiva se conoció en Madrid. ${ }^{1}$ Según el parecer de Alonso, la Soledad segunda debió de escribirse durante 1614; sobre su difusión, en cambio, proporcionó más de una fecha: el mismo año 1614 o bien, aunque lo creyó menos probable, 1617 o 1618 (Góngora 1936, 317-19).

1. Como es sabido el mismo Alonso vaciló al respecto y posteriormente creyó más plausible el año 1613; de la misma opinión son Jammes (Góngora 1994) y Carreira (Góngora 2000). En cambio, Emilio Orozco y Begoña López Bueno defendieron el año 1614 para la fecha en que Almansa y Mendoza difundió el poema por la corte acompañado de sus Advertencias. El problema afecta, asimismo, a la datación de unas décimas gongorinas y del Parecer del abad de Rute. Si se acepta la cronología tardía, el Parecer sería anterior a las Advertencias y no posterior como defendieron Alonso y Jammes. Sobre todo esto, ver las síntesis de Blanco y de Osuna Cabezas 2014. 
La carta en respuesta de Pedro de Valencia, que testimonia la difusión del poema gongorino, se ha conservado en dos testimonios: por un lado, el manuscrito 5585, con texto fechado en junio de 1613, sin indicar día; por el otro, el manuscrito 3906 conocido como Cuesta Saavedra, que transmite un texto fechado en 30 de junio de 1613. Ambos testimonios son autógrafos, se encuentran en la Biblioteca Nacional de España y mencionan la existencia de una lista de lugares defectuosos que se ha perdido. Conviene saber, además, que cada uno de estos documentos representa una redacción distinta. Cuando en 1927 Alonso los estudió, no se sabía con seguridad cuál era el borrador y cuál el texto definitivo, es decir, el texto que Góngora debió de recibir y leer. Los trabajos posteriores de C. C. Smith y, sobre todo, de Pérez López (1921) y Osuna Cabezas $(2008,25-49)$ arrojaron luz sobre esta cuestión: existen indicios seguros, como las referencias temporales implícitas, el diseño estructural o el uso de las citas de versos clásicos, para sostener que el texto del manuscrito 5585 es el borrador y que el texto del manuscrito 3906 representa la redacción final.

En el manuscrito 3906 Pedro de Valencia comienza agradeciendo el encargo de censura y elogiando el ingenio y el arte del nuestro poeta. A continuación, le reprocha que en sus nuevas obras sea contrario a su "natural" y se haya alejado del estilo "claro, liso y gracioso" con el objetivo de oscurecer el poema y extrañar con su erudición incluso a los "más sabidos de su aldea" (Góngora 2000, 464). De manera más específica, Valencia enumera los defectos que ha encontrado en las nuevas creaciones de Góngora: la transposición de vocablos, el uso de palabras "peregrinas" italianas y latinas, la afición por palabras como "peinar", "purpúreo", "si" y "si bien" y, debido a la imitación de italianos y modernos afectados, la inclusión de alusiones burlescas en poemas de materia grave. Tras recomendarle que siga su "natural" y hable con sencillez, claridad, períodos breves y sin transposiciones, se citan cuatro pasajes burlescos -uno del Polifemo y tres de las Soledades- que permitieron a Dámaso Alonso detectar la existencia de una redacción temprana que no coincidía con el texto transmitido en el manuscrito Chacón:

[...] y no me diga que la camuesa pierde el color amarillo en tomando el acero del cuchillo, ni por absolvelle escrúpulos al vaso, ni que el arroyo revoca los mismos autos de sus cristales, ni que las islas son paréntesis frondosos al periodo de su corriente, por más y más que estos dichos y sus semejantes sean los recibidos con mayor aplauso [...]. (Góngora 2000, 565; cursiva original) 
En 1916 Alfonso Reyes localizó y estudió el verso desaprobado del Polifemo en "Los textos de Góngora". Por su parte, tal y como expuso en 1927 en “Góngora y la censura de Pedro de Valencia”, Alonso (1978a) encontró el primer verso censurado de las Soledades en el manuscrito 3795 de la Biblioteca Nacional de España y los otros dos en las Lecciones solemnes de Pellicer, aunque con algún error de copia. ${ }^{2}$

La existencia de una versión primitiva ${ }^{3}$ de la Soledad primera fue confirmada por el descubrimiento de cuatro manuscritos: en primer lugar, el ms. 3266 de la Biblioteca Nacional de Portugal; en segundo lugar, el ms. Arch. Seld. A. II 13 de la Bodleian Library (Oxford); en tercer lugar, el ms. Rm-6709 conservado hoy en la Biblioteca de la Real Academia Española. A estos tres documentos, hay que añadir el ms. 2056 de la Biblioteca de Catalunya, en donde se hallan las variantes de autor inéditas de la Soledad segunda que se dan a conocer con el presente trabajo.

El primero de los manuscritos fue descubierto por el erudito portugués Manuel Rodrigues Lapa. En 1935 este investigador publicó una transcripción diplomática del texto de la Soledad primera contenido en el códice 3266 y afirmó que se trataría de "a primeira ou uma das primeiras versões do célebre

2. El error más evidente, ya estudiado por Alonso (1978a, 510), se encuentra en el verso 205 de la Soledad primera. En las Lecciones solemnes se lee "los mismos altos el de sus cristales" en lugar de "autos", de tal manera que el pasaje pierde todo su significado burlesco, fundamentado en el lenguaje jurídico.

3. El concepto de "versión primitiva" es muy problemático porque Góngora escribía y reescribía sobre la marcha; además, no sabemos con certeza en qué momento empezó a modificar el poema ni la duración de este proceso. El mismo Alonso era consciente de ello: "[...] las Soledades es lo más probable que sufrieran una revisión total a raíz de la censura de Pedro de Valencia; pero su autor siguió luego corrigiéndolas parcamente, sin método y a su sabor: tal vez después de meses el poeta volvía a instalar en la obra un verso que antes había sustituido. Y a todo esto, copias directas, hoy una, al cabo de semanas o meses otra, saldrían de Córdoba e irían difundiéndose y prolificando por España, y como cada una de ellas representaba el estado del poema en el momento en que la copia se sacó, si las conserváramos todas, tendríamos casi tantos textos distintos de la obra (tantas etapas distintas de corrección) como copias directas se hicieron" (Góngora 1936, 335). En adelante, por comodidad y sobre todo porque es expresión aceptada entre los especialistas, me referiré con "versión primitiva" al texto de las Soledades entre 1613 y 1615 a sabiendas de que se trata de un texto fluido y teniendo siempre en mente la definición de "antetexto" empleada en la filología de autor italiana: "Para la filología de autor y la crítica de las variantes la poeticidad del texto no es un «dato», un «valor» establecido, sino, como ya se ha dicho, una «aproximación al valor» que comprende -y es el resultado de- todos los textos que lo han precedido, todos sus antetextos. [...] En la filología de autor aplicada en Italia, en cambio [y a diferencia de la crítica genética francesa], con «antetexto» se indica solo el conjunto de los datos materiales relativos a todo lo que ha precedido el texto" (Italia/Raboni 8). Hay que tener en cuenta, por otra parte, que las modificaciones realizadas por Góngora van más allá del texto leído por Pedro de Valencia y por el abad de Rute. Sobre la cronología, las fases y la existencia de versiones intermedias, actualmente preparo un trabajo de próxima aparición. 
poema" (282). El texto, dividido en tres partes, llega hasta el verso 1031 y no contiene el verso "por absolvelle escrúpulos al vaso" pero sí los otros dos censurados por Pedro de Valencia. Aunque permite corregir alguna corrupción del texto de Pellicer que Alonso tomó como variante de autor, ${ }^{4}$ tras cotejar el manuscrito portugués, puedo afirmar que tampoco está exento de errores de copia y de numerosas variantes de lengua debidas a la influencia del portugués.

El segundo manuscrito que es preciso tener en consideración fue presentado en 1969 por José Ángel Valente y Nigel Glendinning en un artículo titulado "Una copia desconocida de las Soledades". En este trabajo los investigadores describen el ms. Arch. Seld. A. II 13 conservado en la Bodleian Library; la copia transmite la Dedicatoria, la Soledad primera y los primeros 271 versos de la Soledad segunda. La relación entre este manuscrito y el ms. 2056 de la Biblioteca de Catalunya es estrecha porque coinciden en la mayoría de variantes y porque en ambos manuscritos se percibe el trabajo editorial de uno o varios copistas que eliminan pasajes de una versión y añaden versos de otra. Pero también se pueden encontrar divergencias relevantes pues, según Valente y Glendinning (9), en el manuscrito oxfordiano muchas de las intervenciones de los copistas sustituyen la versión definitiva por la primitiva, invirtiendo, de esta manera, el orden temporal; además, en algunas ocasiones se refunden los distintos estados de la obra dando lugar a variantes inéditas, pero que no son de autor.

El manuscrito descubierto en época más reciente que ha permitido conocer mejor los versos enviados a Pedro de Valencia es el Rm-6709; este manuscrito hoy se halla en la Biblioteca de la Real Academia Española, aunque perteneció a Antonio Rodríguez-Moñino. El célebre bibliógrafo dio noticia de su contenido en un artículo publicado en la revista Filología en 1968 con el título "Las Poesías de autores andaluces: manuscrito del siglo XVII". Ahora bien, no fue hasta dos décadas más tarde que Robert Jammes (1984) estudió y divulgó en la revista Criticón la copia de las Soledades contenida en el manuscrito mencionado. En el texto de este manuscrito se pueden distinguir dos manos: una que copia hasta el verso 779 y otra que copia hasta el verso 881 ; sin embargo, los 102 versos añadidos por la segunda mano no fueron transcritos por Rodríguez-Moñino ni completados posteriormente por Jammes en su artículo.

4. Por ejemplo, Alonso $(1936,370)$ imprimió en su edición de la versión primitiva "huye un trecho de sí, se alcanza luego" (v. 206) en lugar de "huye un trecho de sí, alcánzase luego". 
Si bien es cierto que el ms. Rm-6709 permitió conocer versos inéditos de la versión primitiva como los cuatro que siguen tras el número 280 eliminados por Góngora, ${ }^{5}$ su valor reside, en esencia, en que no es una reconstrucción "hecha a partir de copias intermedias" (Jammes 1984, 8) por parte de Dámaso Alonso, sino un documento. Ahora bien, no hay que llamarse a engaño y creer que Rm-6709 sustituye por completo al texto reconstruido y publicado por Alonso. Como ya se ha dicho, esta copia no transmite el poema entero mientras que el texto de 1936 contiene variantes de autor situadas en la Soledad segunda; de ahí que Jammes también lo citara en su edición de 1994.

Llegados a este punto conviene recapitular lo dicho y señalar los pocos hechos que se conocen con seguridad acerca del proceso creativo de las Soledades. En primer lugar, en los trabajos tempranos de Dámaso Alonso se conoce como versión primitiva el texto enviado por Góngora a Pedro de Valencia el 11 de mayo de 1613. La existencia de esta versión se deduce porque en la carta del humanista se censuran tres pasajes de las Soledades que no aparecen en el manuscrito Chacón y que Alonso encontró en el ms. 3795 de la BNE y en las Lecciones Solemnes de Pellicer. En segundo lugar, tras el descubrimiento de Alonso, el erudito portugués Rodrigues Lapa encontró el códice 3266 en la Biblioteca Nacional de Portugal; este documento no contiene un verso censurado por Pedro de Valencia, pero sí los otros dos; la copia, por lo demás, permite enmendar el texto defectuoso de Pellicer. En tercer lugar, hay que tener en cuenta que cuando Alonso editó el texto reconstruido de lo que llamó "versión primitiva" en 1936 no se limitó a utilizar el códice 3266, sino que volvió a valerse del ms. 3795 e incorporó uno nuevo, el 3959. Finalmente, el ms. Rm-6709 permitió a Jammes registrar con un solo manuscrito todos los versos censurados por Pedro de Valencia y dar por bueno -en gran parte, como se verá- el texto de la Soledad primera reconstruido por Alonso en 1936.

\section{EL MS. 2056 DE LA BiBLIOTECA DE CATALUNYA}

Desde la publicación de la edición de 1927, Dámaso Alonso siguió estudiando los indicios existentes del texto temprano de las Soledades. Como ya se ha

5. Los versos son: "seña brillante no de monarquía / el femenil enjambre ostentar deja / a la que en sus dos alas, rubia abeja, / más oro ofrece al día". Hasta donde sé estos versos solo se encuentran en los manuscritos Rm-6709 y 2056. No fueron impresos por Dámaso Alonso en 1936, pero sí por Jammes en su edición de 1994. 
dicho, el resultado de sus esfuerzos fue la edición de 1936 de la versión primitiva del poema a partir de tres manuscritos: el 3795 y el 3959, ambos de la Biblioteca Nacional de España, y el códice 3266 de la Biblioteca Nacional de Portugal. Con la edición de 1936, el manuscrito lisboeta pasó a considerarse el documento que representaba mejor el estado inicial del poema gongorino. Sin embargo, lo fue por poco tiempo porque el mismo Alonso encontró uno mejor que poseía el poeta Joaquín Montaner: el manuscrito Pérez de Rivas. Según Montaner (47), el manuscrito fue adquirido al poco por Artur Sedó i Guichard. Años más tarde, en 1967, la Biblioteca de Catalunya (267) compró todo el fondo Sedó y el manuscrito gongorino pasó a formar parte de la colección con la signatura 2056. Actualmente, se puede acceder a una digitalización del documento a través del portal Memòria Digital de Catalunya ${ }^{6}$

El título con el que se conoce el códice es Obra poética, con algunas correcciones autógrafas, aunque, en realidad, carece de tal inscripción. Cuando Alonso tuvo la oportunidad de estudiarlo y antes de que pasara a manos de Artur Sedó, en una hoja moderna adherida a la guarda de la encuadernación, se podía leer Manuscritos autógrafos de puño y letra de don Luis de Góngora (Alonso 1978b, 463); dicho título no se puede percibir en el estado actual en que se encuentra el códice debido a la encuadernación. Esta se realizó en Brugalla, es de piel roja contemporánea y presenta decoraciones profusas en dorado y cantoneras; en el lomo se lee únicamente "Luis de Góngora / Obras en verso".

El manuscrito se compone de 3 hojas, 479 folios y 3 hojas, es de formato octavo y mide $21 \times 15 \mathrm{~cm}$. En la actualidad se percibe una triple foliación: dos a pluma y una tercera a lápiz. Una de las dos foliaciones a pluma fue realizada por uno de sus propietarios, Gallardo, y es bastante deficiente pues dejó sin numerar las hojas en blanco (Alonso 1978b, 466); la foliación a lápiz es del mismo Alonso; en adelante, utilizaré esta foliación como sistema de referencia.

Un examen más detenido de la foliación permite distinguir, por un lado, que la foliación a pluma de Gallardo y la foliación a lápiz van del folio 6r al 68r; y, por el otro, que solo las tres foliaciones coinciden desde el folio 69r hasta el 414r. A partir de aquí vuelven a aparecer solamente dos foliaciones (la de tinta más antigua y la de Alonso, a lápiz) hasta el folio 479r. En términos generales, si bien la caligrafía de algunos folios como los que van del $175 \mathrm{r}$ al 180r es menos legible, el estado de conservación del manuscrito es bueno y no presenta daños materiales debidos a agentes físicos.

6. <http://mdc.cbuc.cat/cdm/ref/collection/manuscritBC/id/222698>. 
La mayor parte de la información de que disponemos sobre el colector José Pérez de Rivas fue proporcionada por Dámaso Alonso. Cordobés y contemporáneo de nuestro autor, José Pérez de Rivas participó en dos justas poéticas con motivo de la beatificación de Santa Teresa (1614) y en honor de la Concepción (1617); la firma del colector (Ioseph Pz. de Ribas) se halla en el folio 425v (fig. 1). Según Alonso (1978b, 466-68), el manuscrito fue estudiado por Gallardo, Adolfo de Castro y Miguel Artigas; entre los poseedores del códice, se pueden contar Luis Fernández Guerra hacia 1871 y, posteriormente, su hijo Aureliano Fernández Guerra. Ya en el siglo XX el poeta Joaquín Montaner lo adquirió en Madrid. La Biblioteca de Catalunya integró el manuscrito en sus fondos al adquirir la colección de Artur Sedó.

El manuscrito se inicia con tres folios modernos en los que se perciben algunas notas autógrafas de Aureliano Fernández Guerra; en estas se incluye un índice incompleto de los poemas (f. 1r), la copia de 8 versos del romance de Angélica y Medoro (f. 3r) y los títulos del manuscrito Chacón (f. 3v) y de la edición de Vicuña (f. 4r). A continuación, siguen dos índices de poemas que no son de Góngora y de poemas apócrifos pero atribuidos con el membrete "dudase" (f. 5r); probablemente fueron realizados por el mismo colector del manuscrito. Estos índices se complementan con el índice de primeros versos ordenado alfabéticamente y situado al final del códice (ff. $469 \mathrm{v}-78 \mathrm{v})$.

Las Soledades (ff. 6r-27r y 36r-47r) y la Fábula de Polifemo y Galatea (ff. $57 \mathrm{r}-66 \mathrm{v})$ se encuentran al principio del manuscrito. Tras estos siguen otros poemas como los que empiezan por "Tres veces el Aquilón el soplo airado" (f. 67r), "Al tramontar del sol la ninfa mía" (f. 67r), "Con diferencia tal, con gracia tanta" (67v), "De pura honestidad templo sagrado" (f. 68r), tres estrofas del soneto "Valladolid, de lágrimas sois valle," (f. 69r), "Yace debajo de aquesta piedra fría" (f. 69r), etc. No es mi intención dar una relación exhaustiva de su contenido en este trabajo; simplemente bastará con decir que el colector se interesó por todo tipo de poemas, breves y largos, y que su objetivo era formar un codex integrus. Mención aparte merece una colección de "Villancicos de Navidad que se cantaron en la santa iglesia de Córdoba año 1616" (ff. 198r-205v). Por último, debo señalar que el manuscrito también

7. La fecha de composición de los villancicos según Chacón es 1615. Ahora bien, la colección del manuscrito 2056 contiene el villancico Al Nacimiento de Cristo Nuestro señor que empieza con el verso “¡Cuántos silbos, cuántas voces”, fechado tradicionalmente en 1620. 
contiene Las Firmezas de Isabela (ff. 213r-50v), la Fábula de Piramo y Tisbe (ff. 275r-86r) y el Panegírico al duque de Lerma (ff. 406r-14r).

En muchos de los textos se leen añadidos como "De don Luis de Góngora", "Del mismo" o simplemente "sí", que confirman la autoría de los poemas. En menor medida algunas anotaciones al margen refutan que el poema sea obra de Góngora, como en el caso de un poema que empieza por "Señora doña Luisa de Córdoba" (f. 107r) en que se lee "no es del señor Góngora", aunque esta indicación fue tachada y luego se añadió encima "De don Luis de Góngora"; o como en el que empieza por "Aquí yace aunque a su costa" (f. $353 v$ ) en donde se percibe con claridad "No es de don Luis" (fig. 2). En otras ocasiones también se puede leer la indicación "faltan" (ff. 132r, 189r...) y se percibe la intervención del copista que añade epígrafes que aclaran el tema o bien corrige versos (f. 118r). Algunas adiciones, además de negar la autoría de Góngora, al margen proporcionan otro nombre; esto ocurre, al menos, en dos ocasiones: en el poema que empieza por "Pluma menester habéis" (f. 197v), atribuido a Luis Martín, ${ }^{8}$ y en el que empieza por "Céspedes peregrino" (f. 210v), atribuido a don Fernando de Guzmán (fig. 3). El proceso de revisión no es del todo fiable - por ejemplo, dos poemas con motivo de la muerte de Rodrigo de Calderón (f. 315r), que no suelen considerarse gongorinos, se atribuyen a nuestro poeta-, pero es evidente que el colector se esforzó por distinguir cuáles eran los poemas auténticos, y por completar y corregir los textos deturpados.

En realidad, el interés del ms. 2056 es extraordinario por otras razones de mayor peso: por un lado, porque Góngora pudo tener entre sus manos alguno de los cuadernillos y reconocer los poemas de su autoría; por el otro, porque las copias de las Soledades y del Polifemo contienen variantes de autor "del más auténtico gongorismo, que representan también el arranque poético del gran artista, moderado luego por los prudentes consejos de Pedro de Valencia" (Alonso 1978b, 469).

Las intervenciones en que se puede percibir con seguridad la mano de Góngora se limitan a tres lugares, ya estudiados por Alonso. En primer lugar, en el soneto que empieza por "Téngoos, señora Tela, gran mancilla" (91r), Góngora completó dos versos que el copista había dejado parcialmente en blanco; en el tercer verso se puede percibir la adición “¿Cómo estáis acá afuera?” y en el noveno, "Pues ¿qué hacéis ahí?” (fig. 4). En segundo lugar,

8. Mercedes Blanco me sugiere que se trata del poeta antequerano Luis Martín de la Plaza. 
Góngora rechazó la autoría de un poema que empieza "Ya el trato de la verdad" (111v) mediante la adición en el margen "no es mía" debajo de la indicación "De don Luis de Góngora", probablemente, tras tacharla (fig. 5). Por último, en la copia de la letrilla "Un buhonero ha empleado" (196v) faltan dos estrofas, la tercera y la cuarta; Góngora escribió en el margen derecho "faltan" y continuó leyendo hasta que se detuvo para indicar otras estrofas que no eran de su autoría mediante dos rayas horizontales y la adición del comentario "no son mia[s] las que sig[uen]" (fig. 6). Como ya señaló Alonso (1978b, 471-72), esta intervención solo se puede leer si se fuerza un poco la encuadernación ya que el cosido tapa la letra $s$ de "mias" y las últimas letras de "siguen".

En cuanto a las variantes de autor, el ms 2056 confirmó, en gran parte, la reconstrucción de la versión primitiva publicada en 1936 por Alonso. Asimismo, le aportó nuevas variantes de autor desconocidas hasta entonces que divulgó en dos trabajos: el primero fue publicado en 1943 en la revista Correo erudito (Alonso 1943) y solo contaba con un pasaje inédito, el de las gallinas (vv. 303-310); el segundo, de mayor extensión, se titula "La primitiva versión de las Soledades: (tres pasajes corregidos por Góngora)" (Alonso 1978c); en él no solo se recoge nuevamente el pasaje de las gallinas sino que se dan a conocer el de la terneruela (vv. 291-296) y el de las ovejas (vv. 913-918). Los pasajes de las gallinas y de la terneruela se encuentran en el folio 11v (fig. 7). El pasaje de las ovejas se halla en el folio 23r.

Por lo demás, la copia de la Fábula de Polifemo y Galatea contiene algunos vestigios de la versión primitiva. En el folio $58 \mathrm{r}$ aparece tachado el verso censurado por Pedro de Valencia en su Parecer junto con otros tres (X, 77-80 vv.); el pasaje fue desaprobado, como ya se ha dicho, porque en él se equipara de manera chistosa el color de la camuesa con el de una mujer opilada; en el margen hay una adición que lee vide finem. En efecto, los cuatro versos de la versión definitiva fueron transcritos al final del poema (f. 66v). ${ }^{9}$

\section{EL TEXTO DE LAS SOLEDADES}

Las Soledades transmitidas por el ms 2056 de la Biblioteca de Catalunya se extienden desde el folio 6r hasta el folio $47 \mathrm{r}$ de la siguiente manera: Soledad primera (6r-27r), 8 folios en blanco (27v-35v), Soledad segunda (36r-47r). No

9. Para la copia de la Fábula de Polifemo y Galatea que aparece en nuestro manuscrito, ver la edición y estudio de José M. ${ }^{a}$ Micó. 
incluye la dedicatoria al duque de Béjar, solo lleva título la segunda parte del poema (“2 2 Soledad del señor Luis de Góngora”) y está incompleta; el último verso transcrito es el número 558 ("ni del que enciende el mar tirio veneno"). El texto parece copiado por una sola mano, aunque se perciben tres tipos de intervenciones: transcripción, edición y anotación. Como se ha dicho, si bien el ms 2056 tiene interés porque es posible que Góngora completara o corrigiera pasajes, en la copia de las Soledades los tres tipos de intervenciones que analizaré a continuación no pertenecen al poeta cordobés, sino al copista.

En primer lugar, en el plano de la transcripción se observa que la copia fue realizada de manera fragmentaria en cinco fases al menos: el primer intervalo se iniciaría con el primer verso de la Soledad primera ("Era del año la estación florida", 6r) y llegaría hasta el número 943 ("que en letras pocas lean muchos años”, 23v); esta intervención, a su vez, podría dividirse en distintas fases de menor importancia. En el segundo intervalo se añadiría lo que falta de la primera parte del poema hasta el verso 1091 ("a batallas de amor campos de pluma”) con el que termina la primera parte del poema (27r). Con el tercero se dio comienzo a la Soledad segunda (36r) y se siguió con la copia hasta el verso 222 ("De jardín culto así en fingida gruta", 40r). El cuarto intervalo consistiría en el traslado de los versos que siguen hasta "los tesoros que debe" (44r); volveré a él más abajo al comentar las variantes de autor inéditas. Por último, con el quinto se daría fin al traslado del poema en el verso 558 ("ni del que enciende el mar tirio", 47r). Los cambios en el color de la tinta y el estilo caligráfico sustentan estas divisiones en fases aunque, reconozco, el análisis merecería un estudio paleográfico exhaustivo.

En segundo lugar, en el plano de la edición, la misma mano tachó los versos de la versión primitiva y añadió en el margen o encima la versión representada por el manuscrito Chacón. Se trata, por tanto, de una tarea de actualización efectuada por el mismo copista que, en su mayoría, tuvo lugar con posterioridad a la transcripción; por lo general, la tinta es más clara pero la caligrafía es la misma (fig. 8). Este proceso editorial se realizó de manera exhaustiva en la primera parte del poema; en la Soledad segunda, sin embargo, algunas variantes de autor no fueron actualizadas.

En tercer lugar, en el plano de la anotación, se pueden observar un número reducido de notas explicativas realizadas por la misma mano que transcribe y actualiza el poema. Esta anotación se localiza en el margen en tinta más oscura por lo que se deduce que se produjo también con posterioridad. Los folios en los que aparecen notas aclarativas o eruditas son doce: por un 
lado, en los folios 14r, 14v, 15r, 15v, las notas aclaran acontecimientos, referentes geográficos y personajes históricos aludidos en el discurso de las navegaciones; por ejemplo, se menciona a Colón, a Vasco Núñez de Balboa, a Vasco de Gama o a las islas Malucas. Por el otro lado, en los folios 36r, 39r, $39 \mathrm{v}, 41 \mathrm{r}, 42 \mathrm{r}, 43 \mathrm{r}, 43 \mathrm{v}, 45 \mathrm{v}$, en las notas se identifican las fuentes imitadas, se mencionan poetas como Estacio, Claudiano, Séneca, Ascanio, Ovidio, etc. y se citan versos en latín de, entre otras obras, la Eneida, la Ilíada y la Metamorfosis (fig. 9).

La transmisión manuscrita de la poesía gongorina y el trabajo de lima del poeta hacen difícil fechar esta copia de las Soledades. No obstante, me parece plausible conjeturar los términos a quo y ad quem: por un lado, se trataría de una copia que debió de iniciarse hacia 1613 cuando las Soledades aún no habían sido leídas por Pedro de Valencia. Si se tiene en cuenta la extensión de la copia y la cronología conjeturada por Jammes (Góngora 1994), la copia es posterior a las transmitidas en los manuscritos Rm-6709, 3266 y Arch. Seld. A. II 13 descubiertos por Rodríguez Moñino, Rodrigues Lapa y Valente y Glendinning; por el otro lado, teniendo en cuenta como criterio la extensión de la copia, el texto de las Soledades del ms. 2056 es, sin duda, anterior a la edición de Vicuña. Esta edición, como se sabe, solo recoge poemas anteriores a 1617 por lo que se puede tomar esta fecha como término del proceso, aunque creo que existen pruebas suficientes en nuestro códice para fechar la transcripción de la Soledad segunda entre 1614 y 1615.

El cotejo del texto, asimismo, permite confirmar que tres lecciones de la versión primitiva transmitida por el ms. Rm-6709 son errores de copia. Primeramente, en el pasaje sobre el fluir del río censurado por Valencia, el ms. 2056 lee "en brazos dividido caudalosos" (9v); así aparece el verso en la edición de Jammes (Góngora 1994, 240), en donde se afirma en nota que el texto citado corresponde al del ms. Rm-6709; no obstante, en ese códice se lee "en brazos dividido se desata". La lección auténtica es la del manuscrito Pérez de Rivas, que coincide con la que reconstruyó Alonso (Góngora 1936, 371) a partir de las Lecciones solemnes de Pellicer y del manuscrito lisboeta 3266. Nuestro manuscrito también permite confirmar la autenticidad del verso "no ya en la vaca, no en las empulgueras" (11v). ${ }^{10}$ Nuevamente Alonso (Góngora 1936, 374) y Jammes (Góngora 1994, 258) dieron la lección auténtica, aunque

10. Mantengo la puntuación tradicional del pasaje, aunque en nuestro manuscrito se añade una coma tras el segundo adverbio negativo: "No ya en la vaca, no, en las empulgueras". 
el ms. Rm-6709 transmita "no en la boca, no en las empulgueras". No menos importante es el pasaje en que se describen los fuegos artificiales; el ms. Rm6709 transmite "que, cuanto más frenáticos más sanos". En cambio, la lección del ms. 2056 es "frenéticos" (19r). Esta es la lección que imprimieron Dámaso Alonso (Góngora 1936, 384) y Robert Jammes (Góngora 1994, 332) porque también se halla en el ms. 3266 de la Biblioteca Nacional de Portugal.

Gracias al ms 2056 también se pueden corregir cinco lecciones de la versión primitiva reconstruida por Dámaso Alonso. Para empezar en la edición de las Soledades de 1936 se imprimió el verso "en dehesas azules pace estrellas" como el primer estadio del verso número 6. En realidad, como ya señaló Jammes (Góngora 1994, 196), se trata de una "segunda versión”; la lección más temprana se encuentra en el ms 2056 (f. 6r) y en el ms Rm-6709, esto es, "zafiros pisa, si no pace estrellas”. Algo parecido ocurre con el verso 698. La versión más temprana era "papel fue de pastores y no rudo", y como tal se encuentra en el ms. Rm-6709, en el Arch. Seld. A. II 13 y en el 2056 (f. 19r). Sin embargo, Alonso (Góngora 1936, 384) imprimió "papel fue de pastores, si bien rudo" en su edición de la versión primitiva. Tal y como señaló Jammes (Góngora 1994, 334), "si bien rudo" es una versión posterior a "y no rudo" y anterior a la que dan Chacón y la mayoría de manuscritos, es decir, "aunque rudo".

La tercera lección que el ms. 2056 enmienda es el verso 144 de la edición de Alonso (Góngora 1936, 368), a saber: "en boj (que aun descubrir le quiero el torno". En los manuscritos Rm-6709, Arch. Seld. A. II 13 y 2056 (f. 8v) se lee de manera inequívoca "en boj (que aun descubrirle quiso el torno". La lección no fue corregida en la edición de Jammes (Góngora 1994, 226) porque el editor francés dio por bueno el texto reconstruido por Alonso.

Asimismo, el estado primigenio del verso "Tú, Codicia, tú, pues, de las profundas" era ligeramente distinto: "Tú, Codicia, tú, ya aun de las profundas". Esta lección se encuentra como tal únicamente en la copia del ms. 2056 (f. 14v) (fig. 10); en el manuscrito descubierto por Rodrigues Lapa y cotejado por Alonso, el códice 3266, se lee "tuya”. En el ms. Rm-6709 el copista no entendió la lección "tú, ya” y dejó un espacio en blanco de unos pocos centímetros. Alonso imprimió el verso "Tú, Codicia, tú, pues, que de aun profundas" (Góngora 1936, 379). Por su parte, Jammes (Góngora 1994, 288) imprimió el verso que transmite el manuscrito Chacón, es decir, la versión más tardía, sin reparar el error de su predecesor.

Finalmente, también es incorrecto el verso 680 tal y como aparece en la edición de Alonso (Góngora 1936, 384): "la remisión es de su calentura". La 
enmienda ya fue realizada por Robert Jammes (Góngora 1994, 332) porque la lección auténtica ("las remisiones de su calentura") se encuentra tanto en el ms. 2056 (f. 19r) como en el Rm-6709. El error de Alonso se explica porque para el establecimiento de este pasaje solo consultó el ms. 3266, en donde se halla dicha variante de copista.

\section{VARIANTES DE AUTOR INÉDITAS}

El texto de las Soledades contenido en el ms. 2056 de la Biblioteca de Catalunya ha sido estudiado anteriormente por especialistas como Gallardo, Adolfo de Castro y Miguel Artigas. Dámaso Alonso dedicó un importante trabajo a los tres pasajes inéditos de la Soledad primera; sin embargo, no conoció o no divulgó la existencia de seis variantes de autor situadas en la segunda parte del poema. Estas variantes, por tanto, han permanecido inéditas hasta ahora probablemente porque, a excepción de dos, no fueron tachadas y sustituidas por la versión más tardía; es decir, no se distinguen visualmente de su entorno. Pero como los pasajes de las gallinas, la terneruela o las ovejas, obedecen, sin duda, al arranque poético de Góngora antes de recibir los consejos de Pedro de Valencia y, quizá, del abad de Rute.

En lo que sigue daré los pasajes en dos columnas con el objetivo de facilitar el análisis de la revisión y la comparación entre los distintos estados. En la columna izquierda sitúo una modernización del texto transmitido en el ms. 2056 y en la columna derecha cito la versión definitiva editada por Robert Jammes; he marcado con cursiva los versos que contienen la variación textual.

El primer pasaje se encuentra en el folio 41r del manuscrito 2056 y corresponde a descripción del álamo en el que se construyó un palomar de mimbres. Esta construcción se parece a un garbín, es decir, a una especie de cofia con que las mujeres se recogían y adornaban el cabello (vv. 263-271):

Hermana de Faetón, verde el cabello, bien que de mimbres preso en garvín pardo álamo, digo, mostró gallardo, que desde el mar pudiera [negar] bello.
Hermana de Faetón, verde el cabello, les ofrece el que, joven ya gallardo de flexiiosas mimbres garbin pardo tosco le ba encordonado, pero bello. 
Lo más liso trepó, lo más sublime venció su agilidad, y artificiosa tejió en sus ramas inquïetos nidos, donde celosa arrulla y ronca gime la ave lasciva de la cipria diosa.
Lo más liso trepó, lo más sublime venció su agilidad, y artificiosa tejió en sus ramas inconstantes nidos, donde celosa arrulla y ronca gime la ave lasciva de la cipria diosa.

Como se puede observar con facilidad, la reescritura del pasaje supuso la eliminación de la fórmula concesiva introducida por "bien que" y del término metaforizado (“álamo”). En la versión definitiva Góngora, pues, prefiere la partícula "ya", que sitúa temporalmente la acción, ${ }^{11}$ nos ofrece únicamente la expresión metaforizante ("Hermana de Faetón"), incrementando así la dificultad del pasaje, pero en cambio refiere quién fue el responsable de la construcción del palomar, es decir, el pescador en sus años de juventud. Además, con la revisión se suprimió el verbo dicendi (“digo”) y, en consecuencia, se pasó de la primera persona a la tercera, de la expresión del yo a una representación de objetos. No hay que olvidar, por último, que Góngora sustituyó el adjetivo "inquïetos" por "inconstantes". Puesto que en la versión definitiva empleó el término "flexüosas", el objetivo no fue deshacerse de la diéresis sino evitar la acumulación de dos diéresis en un mismo pasaje.

El ms. 2056, sin embargo, plantea un problema en este verso: el término "negar" no es legible. De hecho, si se realiza una lectura literal, habría que leer: "que desde el mar pudiera megor bello" (fig. 11). Pero "megor" (o "mejor") no tiene ningún sentido, así que creo que se trata de un error de copia y que el original debía de leer "negar". He llegado hasta este término a partir de la versión definitiva en la que se afirma que el "garvín" es "tosco pero bello". Mi hipótesis es que en la primera versión se encuentra de manera latente y sugerida esta oposición: desde la barca en que se halla el peregrino se puede negar la belleza del artificio, pero no cuando se contempla de cerca. En la versión definitiva, por tanto, la oposición se expresa de una manera más condensada mediante la preposición "pero".

El segundo pasaje se halla en el folio 42v del manuscrito 2056; en él se describe el lugar rodeado por unos chopos y cubierto de lirios en el que el peregrino y el pescador se disponen a comer (vv. 328-336):

11. Resulta curioso que Góngora sustituyera la partícula "bien” por "ya" teniendo en cuenta que el abad de Rute censuró el uso de ambos términos en su Parecer. 
Seis chopos, de seis hiedras abrazados, tirsos eran del griego dios, nacido segunda vez, que en pámpanos desmiente los cuernos de su frente; y cual mancebos tejen anudados festivos corros en alegre ejido, el suelo ellos coronan impedido de blancos lilios, que en fragantes copos nevó el Mayo, a pesar de los seis chopos.
Seis chopos, de seis yedras abrazados, tirsos eran del griego dios, nacido segunda vez, que en pámpanos desmiente los cuernos de su frente; y cual mancebos tejen anudados festivos corros en alegre ejido, coronan ellos el encanecido suelo de lilios, que en fragrantes copos nevó el Mayo, a pesar de los seis chopos.

En esta ocasión, al reescribir el pasaje, Góngora suprimió un hipérbaton, movió el término "suelo" hacia el verso siguiente y sustituyó la voz "impedido", que había aparecido en cuatro ocasiones a lo largo del poema, por "encanecido". Al emplear "encanecido", además, el texto ganó variedad y el poeta pudo eliminar el epíteto "blancos" porque el nuevo término ya sugiere el color de los lirios. El poeta, pues, prefiere aquí una expresión más clara y sugerir de manera indirecta el color de las flores.

El tercer pasaje es contiguo al precedente y se encuentra también en el folio 42v del ms. 2056. Se trata de uno de los dos pasajes inéditos que sí fueron actualizados mediante un tachón y dos adiciones, encima y en el margen (fig. 12). En él se describen los modos en que el peregrino y el viejo pescador se sientan, se relajan y disfrutan de los alimentos (vv. 337-348):

Este sitio las bellas seis hermanas escogen, agraviando

en breve espacio mucha Primavera con las mesas, cortezas ya livianas del árbol que ofreció a la edad primera duro alimento, pero sueño blando. Nieve hilada, y por sus manos bellas caseramente a telas reducida, manteles blancos fueron.

Sentados, pues, los cuatros en corchos, ellas con pocas ceremonias la comida mas con silencio mucho les sirvieron.
Este sitio las bellas seis hermanas escogen, agraviando en breve espacio mucha Primavera con las mesas, cortezas ya livianas del árbol que ofreció a la edad primera duro alimento, pero sueño blando. Nieve hilada, y por sus manos bellas caseramente a telas reducida, manteles blancos fueron. Sentados pues sin ceremonias, ellas en torneado fresno la comida con silencio sirvieron.

En el primer estado del pasaje eran cuatro personajes los que se sentaban en la mesa y las hijas del pescador las que servían la comida "con pocas ceremonias" 
y "mucho silencio". Con la reescritura del pasaje se eliminó el cuantitativo "cuatro" y se modificó el modo con que la comida fue servida, desplazando esta información hacia arriba: si en la versión inicial las ceremonias eran "pocas", en la definitiva la comida se sirve "sin" ceremonias en concordancia con el ideal de austeridad del viejo pescador. En la primera redacción, por tanto, había una oposición entre las "pocas ceremonias" y el "mucho silencio", que podía resultar pesada para el lector; en la final, los modos austeros se intensifican, pero también el placer de disfrutar de la comida sin los molestos rituales cortesanos.

Además, al revisar el pasaje Góngora añadió un elemento nuevo: el "torneado fresno", es decir, la escudilla utilizada por las hijas del viejo pescador. La aparición de este utensilio se debe, sin duda, al gusto del poeta por los pequeños detalles y debe leerse en relación con la escudilla de boj y la cuchara de los versos 143-152 de la Soledad primera.

El cuarto pasaje se localiza en el folio 43v del ms. 2056 y corresponde a las palabras del viejo pescador que, tras agradecer a la divina Providencia por los alimentos recibidos, ahora exhorta al peregrino a quedarse en tierra y a no volver a navegar (vv. 367-387):

Pisad dichoso esta esmeralda bruta en mármol engastada siempre undoso, jubilando la red en los que os restan felices años, y la humedecida, o poco rato enjuta, próxima arena de esa opuesta playa la remota Cambaya sea de hoy más a vuestro leño ocioso; y el mar que os la divide, cuanto cuestan océano importuno

a las quinas gloriosas sus ardientes veneros, su esfera lapidosa de luceros.
Pisad dichoso esta esmeralda bruta en mármol engastada siempre undoso, jubilando la red en los que os restan felices años, y la humedecida, o poco rato enjuta, próxima arena de esa opuesta playa la remota Cambaya sea de hoy más a vuestro leño ocioso; y el mar que os la divide, cuanto cues$\tan$

Océano importuno a las Quinas (del viento aun veneradas) sus ardientes veneros, su esfera lapidosa de luceros. 
Del pobre albergue a la barquilla pobre, geómetra prudente, el orbe mida vuestra planta, impedida, en trágicas rüinas lastimosas del frágil pino, del velero robre, que (el tridente acusando de Neptuno) menos dieron astillas que ejemplos de dolor a estas orillas.

\author{
Del pobre albergue a la barquilla po- \\ bre, \\ geómetra prudente, el orbe mida \\ vuestra planta, impedida, \\ si de purpúreas conchas no istriadas, \\ de trágicas rüinas de alto robre, \\ que (el tridente acusando de Nep- \\ tuno) \\ menos quizá dio astillas \\ que ejemplos de dolor a estas orillas.
}

Según Jammes (Góngora 1994, 474), el verso "a las Quinas (del viento aun veneradas)" es una alusión a Las Lusíadas y a la diosa Venus. El resultado final es, sin duda, mucho más elevado ya que se sustituye un adjetivo bastante prosaico como "gloriosas" por uno más elegante como "veneradas"; por otra parte, al transformar el heptasílabo en un endecasílabo, Góngora aprovechó para incluir un hipérbaton (“del viento aun veneradas") y enriquecer la expresión con aliteraciones y paranomasias (viento-veneradas-veneros).

La reescritura de los versos 377 y 383 están relacionadas por la rima. Al sustituir "gloriosas" por "veneradas" Góngora tuvo que sustituir también "lastimosas" por "istriadas". La revisión de los versos 383 y 384, sin embargo, fue más allá de este problema métrico porque toda la elocución se volvió más extraña y el estilo más sublime. Para empezar, Góngora decidió incluir, pese al consejo de Pedro de Valencia, una construcción del tipo "si A, no B" y volvió a utilizar el adjetivo "purpúreas". En la versión definitiva el pasaje, además, gana en variedad y riqueza gracias al adjetivo "istriadas". No deja de ser significativo, por lo demás, el contraste entre la concepción del mar como amenaza que aparece en la versión primitiva y la belleza con que se describe la playa por donde camina el pescador en la versión definitiva.

En cuanto a la modificación del verso "del frágil pino, del velero robre", nos encontramos con la misma estrategia que en los versos 263-271; el referente ("velero") vuelve a desaparecer en la versión definitiva. En su lugar se recuperan las "trágicas rüinas" que en la primera versión se hallaban en el verso precedente. Con la reescritura del pasaje, estas "trágicas rüinas" pasan a ser el sujeto de la oración y, por tanto, Góngora modificó el número del verbo ("dieron" por "dio"); la adición del "quizá" se debe, creo, a razones métricas, aunque no hay que descartar el efecto atenuador sobre la hipérbole que conlleva el uso de este adverbio. 
El quinto pasaje se encuentra en el folio 44r del ms. 2056 y corresponde, nuevamente, a las palabras del viejo pescador. Se trata de uno de los dos pasajes actualizados mediante tachaduras y adiciones encima (fig. 13). En concreto, las palabras "si no sediento" y "que avariento" fueron tachadas; encima se perciben las adiciones de "ese profundo" y "sediento". A mi juicio, la actualización del pasaje y la transcripción de los versos que siguen fueron realizadas de manera coordinada por la misma mano: antes de seguir transcribiendo, el amanuense tachó los versos "en túmulos pagó de espuma breve / los tesoros que debe" y debajo copió "cuanto en vasos de abeto Nuevo Mundo / (tributos digo américos) se bebe / en túmulos de espuma paga breve"; en esta ocasión, pues, el plano de la transcripción y de la edición se confunden. En cuanto al significado de los versos, en este pasaje el anciano pescador relata su retiro (vv. 388-406) antes de dar cuenta de las hazañas de una de sus hijas:

"Días ha muchos, oh mancebo -dijo el pescador anciano-, que en el uno cedí y el otro hermano el duro remo, el cáñamo prolijo: muchos ha dulces días que cisnes me recuerdan a la hora que, huyendo la Aurora las canas de Titón, halla las mías (a pesar de mi edad) no en la alta cumbre de aquel morro difícil (cuyas rocas tarde o nunca pisaron cabras pocas, y milano venció con pesadumbre), sino desotro escollo al mar pendiente, de donde ese teatro de Fortuna descubro, ese voraz, si no sediento campo ya de sepulcros, que, avariento, en túmulos pagó de espuma breve los tesoros que debe.

\author{
"Días ha muchos, oh mancebo -dijo \\ el pescador anciano-, \\ que en el uno cedí y el otro hermano \\ el duro remo, el cáñamo prolijo: \\ muchos ha dulces días \\ que cisnes me recuerdan a la hora \\ que, huyendo la Aurora \\ las canas de Titón, halla las mías \\ (a pesar de mi edad) no en la alta cumbre \\ de aquel morro difícil (cuyas rocas \\ tarde o nunca pisaron cabras pocas, \\ y milano venció con pesadumbre), \\ sino desotro escollo al mar pendiente, \\ de donde ese teatro de Fortuna \\ descubro, ese voraz, ese profundo \\ campo ya de sepulcros, que, sediento, \\ cuanto en vasos de abeto Nuevo Mundo \\ (tributos digo américos) se bebe \\ en túmulos de espuma paga breve.
}

La reescritura del pasaje quizá se deba a la censura de Pedro de Valencia ya que Góngora eliminó la conjunción "si”. Lo que sí es seguro es que el poeta reutilizó el material de la primera tentativa: en primer lugar, se deshizo del adjetivo "avariento" pero no de "sediento"; la idea de voracidad, que solo se 
insinuaba en la versión primitiva, cobra mayor relevancia tras la revisión gracias a la metáfora del "vaso de abeto" para referirse a los veleros que naufragan. En segundo lugar, como es evidente, Góngora creó un nuevo verso en el que se menciona de manera explícita al "Nuevo Mundo"; también hizo la sintaxis más compleja al introducir la partícula "cuanto" y hacer la frase más larga. En tercer lugar, el paso de la primera versión a la definitiva también supuso la actualización de los hechos, que ahora llegan hasta el presente de la narración ("pagó"-"paga"). En cuarto lugar, al contrario de la estrategia llevada a cabo en el pasaje 263-271, en este se sustituyó el término "tesoros" por una expresión irónica ("tributos digo américos") emergiendo, así, la voz poética en primera persona; la metáfora monetaria ya estaba en la primera versión en el uso del término "avariento" pero en la final, al encadenarse las metáforas de la sed y del dinero, el resultado es más complejo, coherente y rico en significaciones; por otro lado, es bastante probable que estemos ante un chiste conceptuoso pues el término "vaso" se emplea con doble sentido, es decir, como barco y como recipiente que el mar se bebe. En quinto lugar, hay que tener en cuenta que la expresión "campo ya de sepulcros" no fue eliminada pese a que contiene una partícula "ya" censurada por el abad de Rute en su Parecer.

Finalmente, el sexto pasaje se encuentra en el folio $45 \mathrm{r}$ del ms. 2056. En los versos que cito (vv. 445-452) el viejo pescador relata cómo una de sus hijas, Éfire, se lanza al mar para cazar:

Éfire luego, la que en el torcido luciente nácar te sirvió no poca risueña parte de la dulce fuente (de Filódoces émula valiente, cuya asta breve desangró la foca), el cabello en estambre azul cogido, alcaide el cielo de sus trenzas de oro, en segundo bajel se engolfó sola.

\author{
Éfire luego, la que en el torcido \\ luciente nácar te sirvió no poca \\ risueña parte de la dulce fuente \\ (de Filódoces émula valiente, \\ cuya asta breve desangró la foca), \\ el cabello en estambre azul cogido, \\ celoso alcaide de sus trenzas de oro, \\ en segundo bajel se engolfó sola.
}

Nuevamente, como en los vv. 263-271, Góngora reescribió un verso sobre la forma de recoger y adornar el cabello femenino. En esta ocasión, sin embargo, la modificación fue mínima y consistió en la sustitución de la expresión "alcaide el cielo" por "celoso alcaide" para referirse al estambre azul con que Éfire se ató el pelo antes de salir a cazar. Según Robert Jammes (Góngora 1994, 482), Salcedo entendió que Góngora llamaba “celoso" al estambre de- 
bido a la similitud de las rejas de las celosías; en cambio, Pellicer fue de la opinión que la metáfora se sustentaba en el color azul. Es probable que Góngora no se sintiera satisfecho y decidiera desprenderse de la semejanza cromática en favor de una semejanza basada en el temperamento que, por lo demás, ponía el acento en la personificación del estambre.

$\mathrm{El}$ análisis de estas seis variantes de autor inéditas confirma en gran parte lo que ya sugirieron Robert Jammes (1995) y Joaquín Roses. Si bien es cierto que Góngora modificó los chistes censurados por Pedro de Valencia y otros situados en la primera parte del poema, la reescritura de estos pasajes no se debe a su naturaleza burlesca; a mi juicio, el poeta tomó buena nota de la censura del humanista de Zafra y sus palabras influyeron en la misma escritura de los versos que aún quedaban por escribir cifrándolos con una elocución más poética. Como ya se ha dicho, es posible ver en la versión definitiva de los versos 388-406 -en que el naufragio de veleros se representa en términos económicos y mercantiles- un chiste conceptuoso, pero enmascarado por el estilo, hasta el punto que se vuelve casi imperceptible.

La revisión de estas variantes inéditas se debe fundamentalmente a la voluntad de perfeccionar el poema. En dos casos (el pasaje de la cofia y el de los veleros que se bebe el mar), esto se lleva a cabo por medio de la sustitución de las partículas adversativas ("bien" o "si") censuradas por Pedro de Valencia y, más tarde, por el abad de Rute; pero en la mayoría el motivo principal es el enriquecimiento de una idea. En cuanto a los otros rasgos de estilo censurados, en versos como "les ofrece el que, joven ya gallardo", "a las Quinas (del viento aun veneradas)", "de flexüosas mimbres garbín pardo", "si de purpúreas conchas no istriadas" y "campo ya de sepulcros, que, sediento" el poeta añadió en la versión final algún hipérbato, no eliminó cultismos o diéresis, siguió utilizando construcciones adversativas y repitió algunas de las palabras censuradas. La revisión, pues, no fue ciega sino crítica y meditada. Obedeció también al afán de crear nuevos paralelismos y recurrencias entre la Soledad primera y la Soledad segunda; de ahí que algunas modificaciones solo se entiendan si se leen de manera correlativa, es decir, como si el poema fuera un sistema en transformación.

En definitiva, Góngora reescribió algunos pasajes con el objetivo de aligerar el poema de construcciones adversativas, tal y como le recomendaron sus lectores de confianza, a fin de dotar al texto de mayor diversidad; pero, sobre todo, reescribió para desarrollar, intensificar o fortalecer una idea que ya se encontraba en la primera redacción o en otro lugar del poema. 


\section{CONCLUSIONES}

A lo largo del siglo XX una serie de descubrimientos han permitido conocer con mayor precisión el proceso creativo de las Soledades. A partir de los versos citados por Pedro de Valencia, Dámaso Alonso empezó a investigar el estado primitivo del poema y cotejó los manuscritos 3795 y 3959 de la Biblioteca Nacional de España, las Lecciones Solemnes de Pellicer y el ms. 3266 de la Biblioteca Nacional de Portugal. Posteriormente, el mismo Alonso consultó el ms. 2056 de la Biblioteca de Catalunya y dio a conocer tres pasajes inéditos.

A partir de los años sesenta otros investigadores (Valente, Glendinning, Jammes, etc.) se sumaron a la empresa y estudiaron nuevos manuscritos; así las cosas, es probable que el descubrimiento del ms. Rm-6709 eclipsara la importancia del 2056 hasta el punto de caer en el olvido. Dámaso Alonso prometió en varias ocasiones que reeditaría las Soledades y quién sabe si esa nueva edición, que nunca vio la luz, contendría las seis variantes inéditas analizadas aquí. En cualquier caso, el ms. 2056 tiene una importancia que no posee ninguno de los manuscritos tempranos que transmiten las Soledades. Para empezar, es un códice creado en un ambiente cercano a Góngora y algunos de sus cuadernos fueron leídos por el mismo poeta; es más, entre sus páginas se encuentran unas pocas correcciones autógrafas que rechazan algunos poemas atribuidos y completan lagunas en otros.

Pero sin duda el mayor interés que posee el ms. 2056 de la Biblioteca de Catalunya es que la copia de las Soledades nos permite conocer el estado del poema entre 1613 y 1615. La transcripción fue realizada en varios intervalos, quizá porque el envío de los versos también lo fuera. Se percibe una esmerada tarea editorial consistente en la actualización de los versos y un afán por anotar el texto a fin de aclarar los pasajes más difíciles o bien descubrir las fuentes imitadas. El propietario del manuscrito no solo era un ferviente admirador de Góngora sino también un hombre culto y preocupado por poseer poemas auténticos y la última voluntad del poeta cordobés. Esta copia de las Soledades permite corregir tres lecciones corruptas del ms. Rm-6709 y cinco lecciones de la versión primitiva publicada por Dámaso Alonso en 1936.

Los seis pasajes de la Soledad segunda que contienen variantes de autor inéditas participan del arranque poético de Góngora anterior a los consejos de Pedro de Valencia y, quizás, del abad de Rute. En términos generales, la reescritura de estos pasajes no tuvo como finalidad eliminar una alusión burlesca; antes al contrario, es posible que en un lugar del poema Góngora añadiera en 
la versión final un chiste conceptuoso difícil de percibir. El poeta no eliminó de manera sistemática las partículas censuradas y tampoco evitó los cultismos, las transposiciones o la repetición de algunas palabras. Las modificaciones analizadas responden de manera fundamental a la voluntad de mejorar la obra; en esta parte del poema, pues, la revisión sirvió para intensificar una idea de la versión primitiva o bien para crear nuevos paralelismos entre la Soledad primera y la Soledad segunda. Por estos motivos el ms. 2056 de la Biblioteca de Catalunya es la mejor ventana que hoy tenemos para asomarnos al taller del poeta.

\section{OBRAS CITADAS}

Alonso, Dámaso. "Primitiva versión de las Soledades: un pasaje inédito". Correo erudito 3 (1943): 61-62.

Alonso, Dámaso. "Góngora y la censura de Pedro de Valencia”. Obras completas. Vol. 5. Madrid: Gredos, 1978a. 495-517.

Alonso, Dámaso. "Puño y letra de don Luis en un manuscrito de sus poesías". Obras completas. Vol. 5. Madrid: Gredos, 1978b. 463-72.

Alonso, Dámaso. "La primitiva versión de las Soledades: tres pasajes corregidos por Góngora”. Obras completas. Vol. 5. Madrid: Gredos, 1978c. 485-94.

Biblioteca de Catalunya. 100 anys. 1907-2007. Biblioteca de Catalunya: Barcelona, 2007.

Blanco, Mercedes. "La polémica en torno a Góngora (1613-1630): el nacimiento de una nueva conciencia literaria". Mélanges de la Casa de Velázquez 42.1 (2012): 49-70. 4 de abril de 2016. <http://mcv.revues. org/4255>.

Góngora, Luis. Soledades. Ed. Dámaso Alonso. Madrid: Revista de Occidente, 1927.

Góngora, Luis. Las Soledades. Ed. Dámaso Alonso. Madrid: Cruz y Raya, 1936.

Góngora, Luis. Soledades. Ed. Robert Jammes. Madrid: Castalia, 1994.

Góngora, Luis. Obras completas. Ed. Antonio Carreira. Vol. 2. Madrid: Fundación José Antonio de Castro, 2000.

Italia, Paola, y Giulia Raboni. “¿Qué es la filología de autor?”. Creneida 2 (2014): 7-56.

Jammes, Robert. "Un hallazgo olvidado de Antonio Rodríguez Moñino: la primera redacción de las Soledades". Criticón 27 (1984): 5-35. 
Jammes, Robert. "Apuntes sobre la génesis textual de las Soledades". Crepúsculos pisando: once estudios sobre las "Soledades" de Luis de Góngora. Ed. Jacques Issorel. Perpiñán: CRILAUP, 1995. 121-39.

López Bueno, Begoña. "El cruce epistolar entre Lope y Góngora de 16151616: revisión de fechas”. El poeta Soledad. Ed. Begoña López Bueno. Zaragoza: Prensas Universitarias de Zaragoza, 2011. 239-70.

Micó, José M. '. El "Polifemo" de Luis de Góngora: ensayo de crítica e bistoria literaria. Barcelona: Península, 2001.

Montaner, Joaquín. La colección teatral de don Arturo Sedó. Barcelona: Seix y Barral hnos., 1951.

Orozco, Emilio. En torno a las "Soledades". Granada: Universidad de Granada, 1969.

Osuna Cabezas, María José. Las "Soledades" caminan hacia la corte: primera fase de la polémica gongorina. Vigo: Editorial Academia del Hispanismo, 2008.

Osuna Cabezas, María José. "La polémica gongorina: estado de la cuestión y tareas pendientes". El universo de Góngora: orígenes, textos y representaciones. Ed. Joaquín Roses. Córdoba: Diputación de Córdoba, 2014. 417-53.

Pérez López, Manuel María. Pedro de Valencia, primer crítico gongorino: estudio y edición anotada de la "Carta a Góngora en censura de sus poesías". Salamanca: Ediciones Universidad de Salamanca, 1988.

Reyes, Alfonso. "Los textos de Góngora". Boletín de la Real Academia Española 3.13-14 (1916): 257-71 y 510-25.

Rodrigues Lapa, Manuel. "Uma versão desconhecida da 1"a Soledad de Góngora". Boletim de Filologia 3 (1935): 281-317.

Rodríguez-Moñino, Antonio. "Las Poesías de autores andaluces: manuscrito del siglo XVII”. Filología 13 (1968-1969): 305-28.

Roses, Joaquín. Góngora: "Soledades" habitadas. Málaga: Universidad de Málaga, 2007.

Smith, C. C. "Pedro de Valencia's Letter to Góngora". Bulletin of Hispanic Studies 39.2 (1962): 90-91.

Valente, José Ángel, y Nigel Glendinning. "Una copia desconocida de las Soledades". Bulletin of Hispanic Studies 36.1 (1959): 1-14. 4 de abril de 2016. <http://online.liverpooluniversitypress.co.uk/doi/abs/10.3828/ bhs.36.1.1>. 

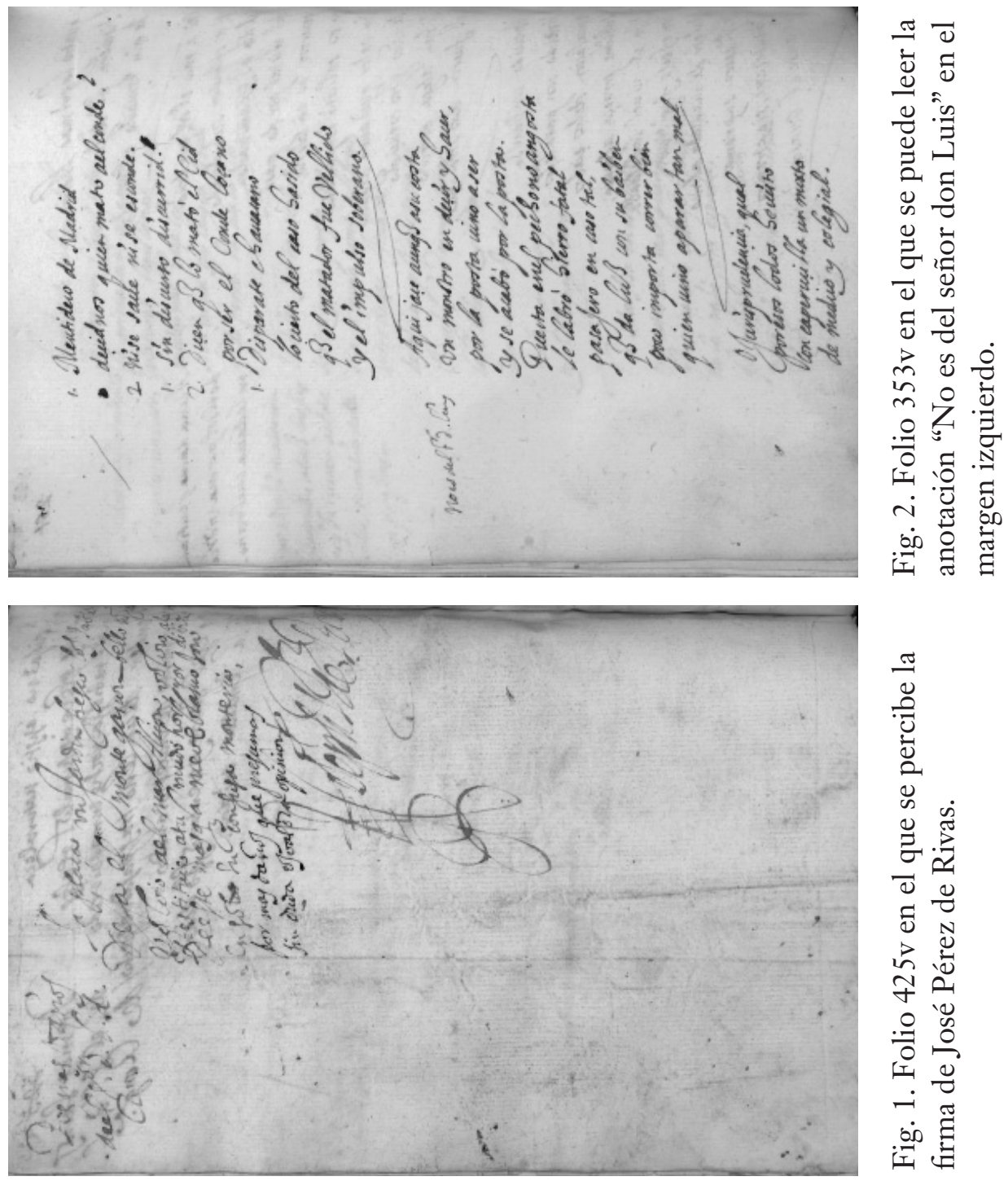

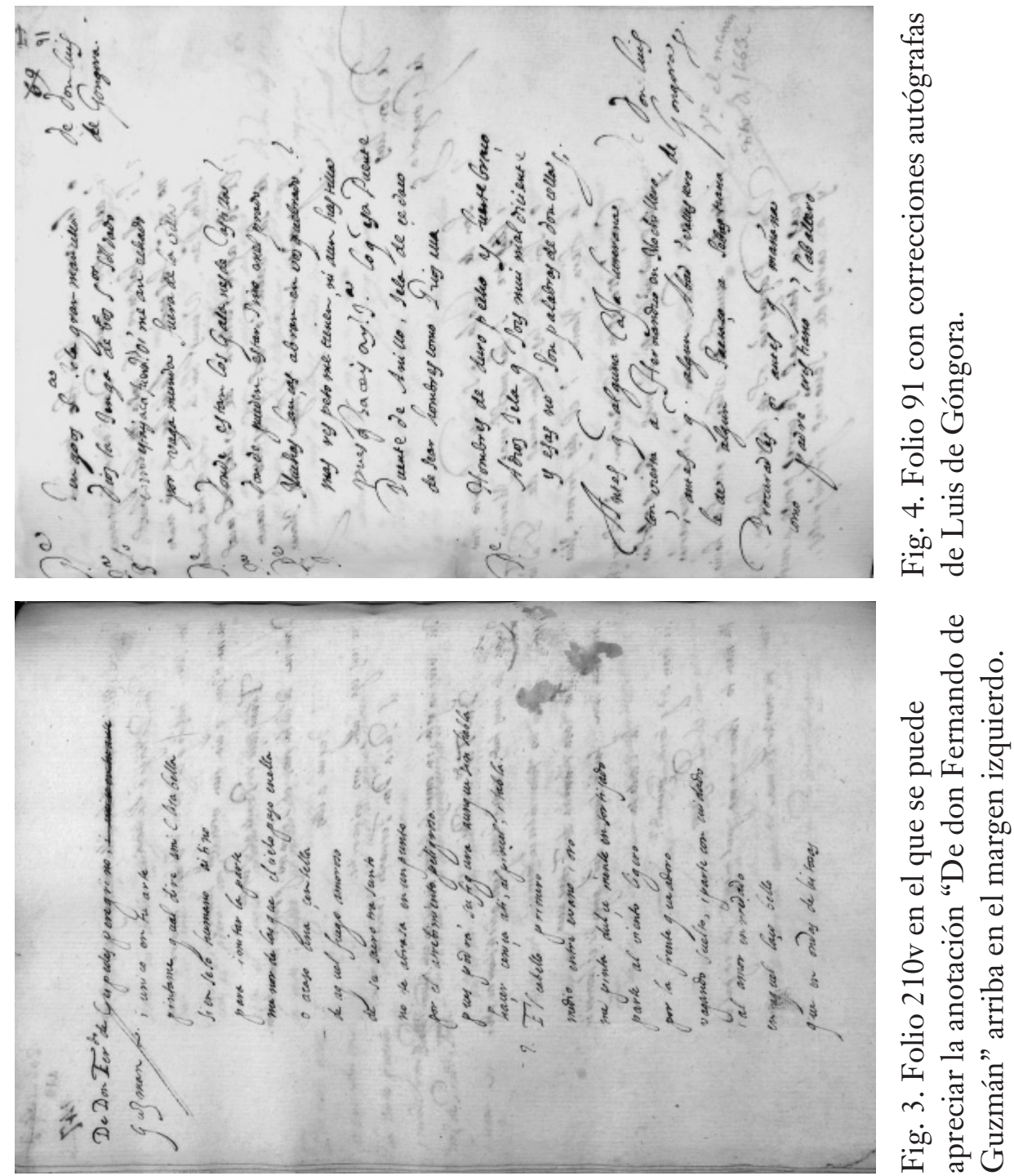

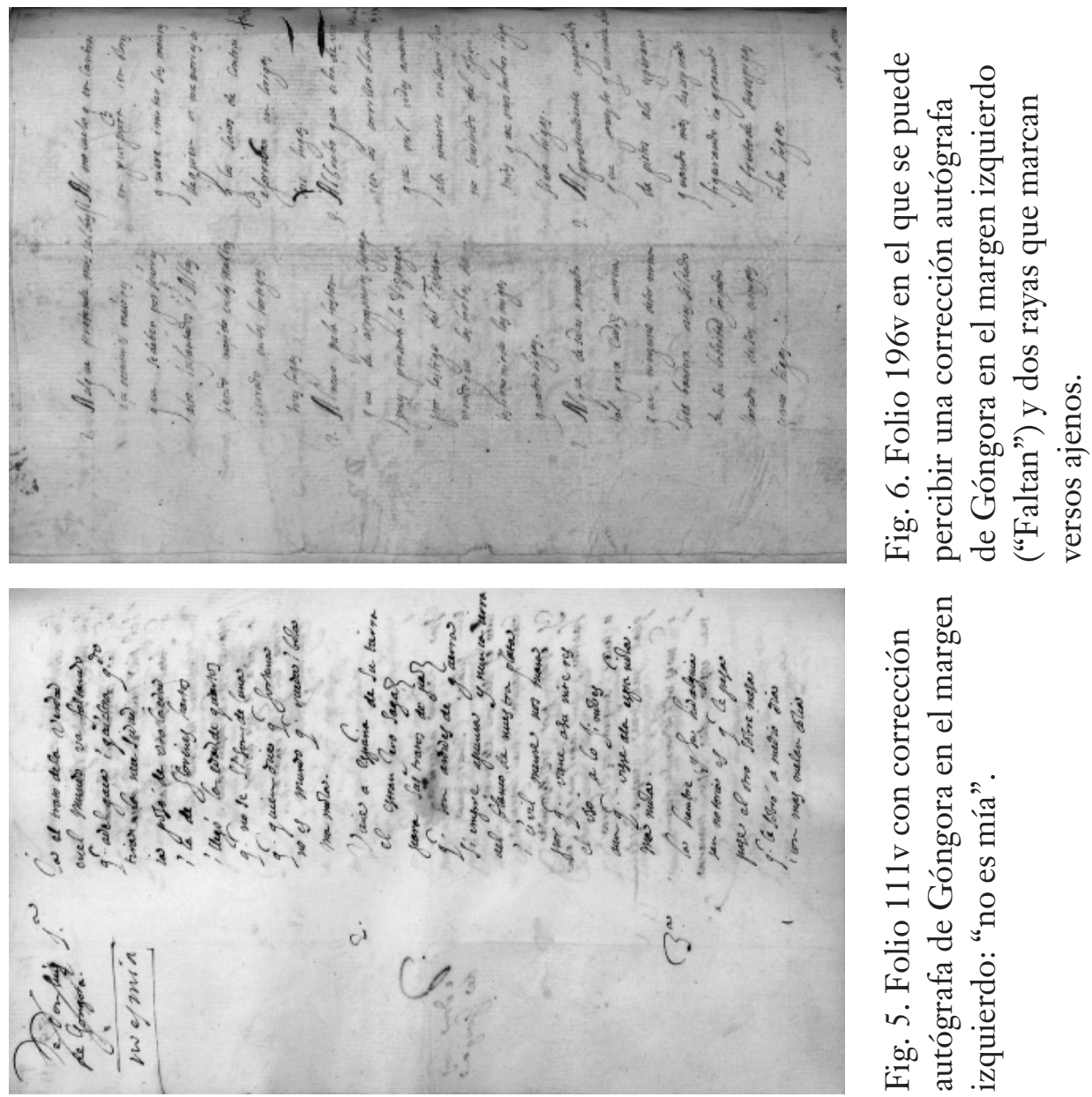

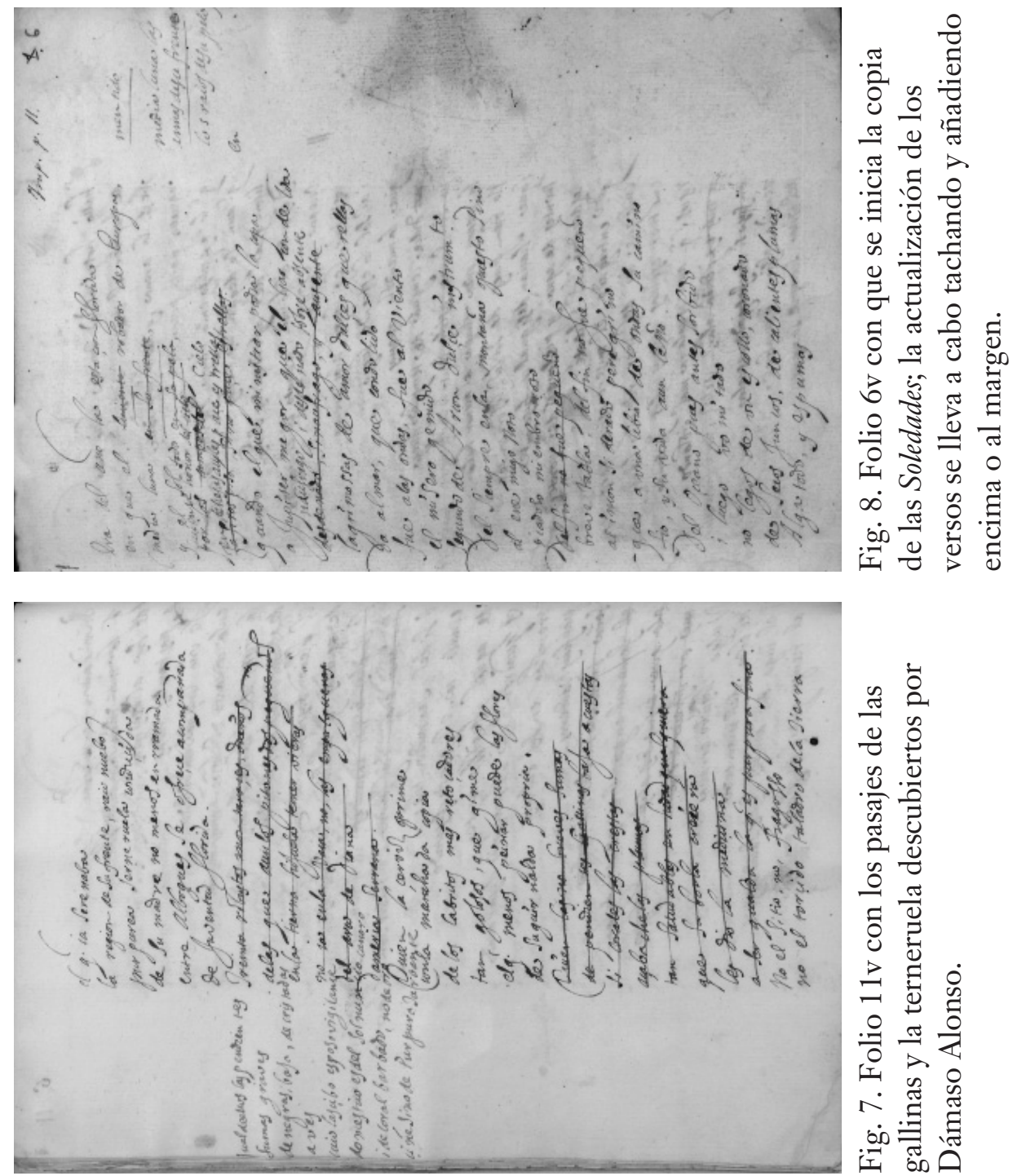

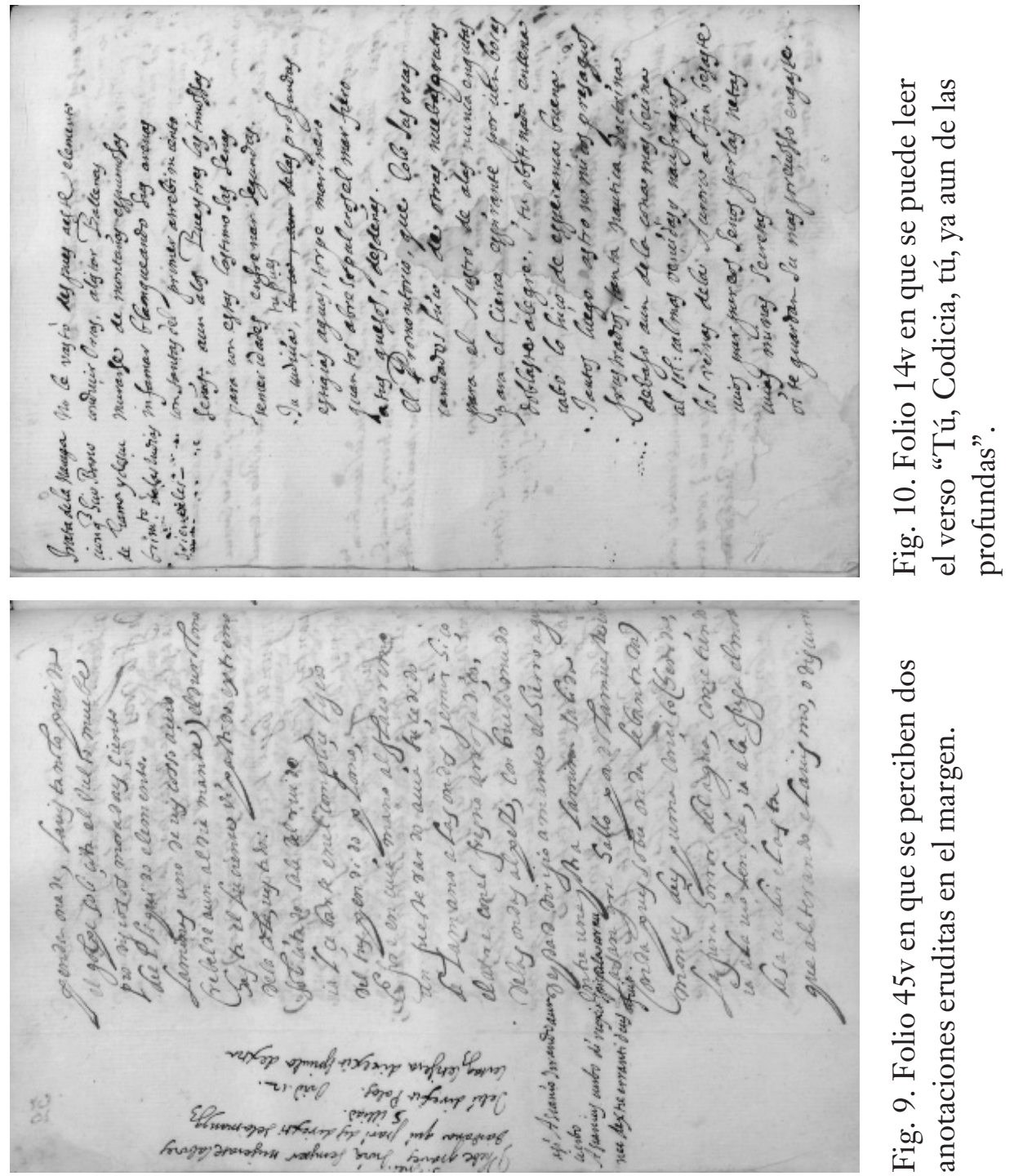

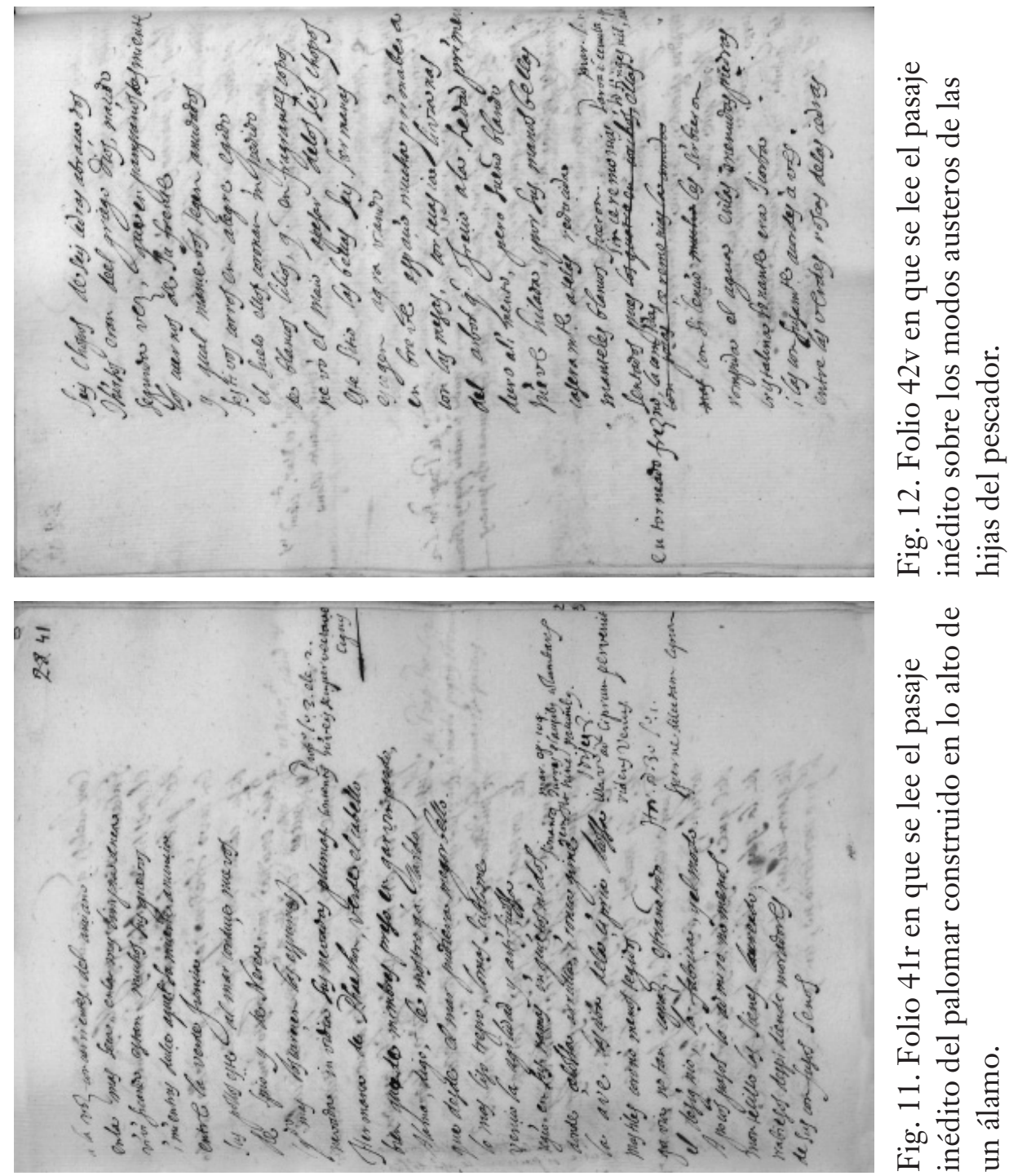
ROJAS. LAS SOLEDADES DE GÓNGORA EN EL MS. 2056 DE LA BIBLIOTECA DE CATALUNYA

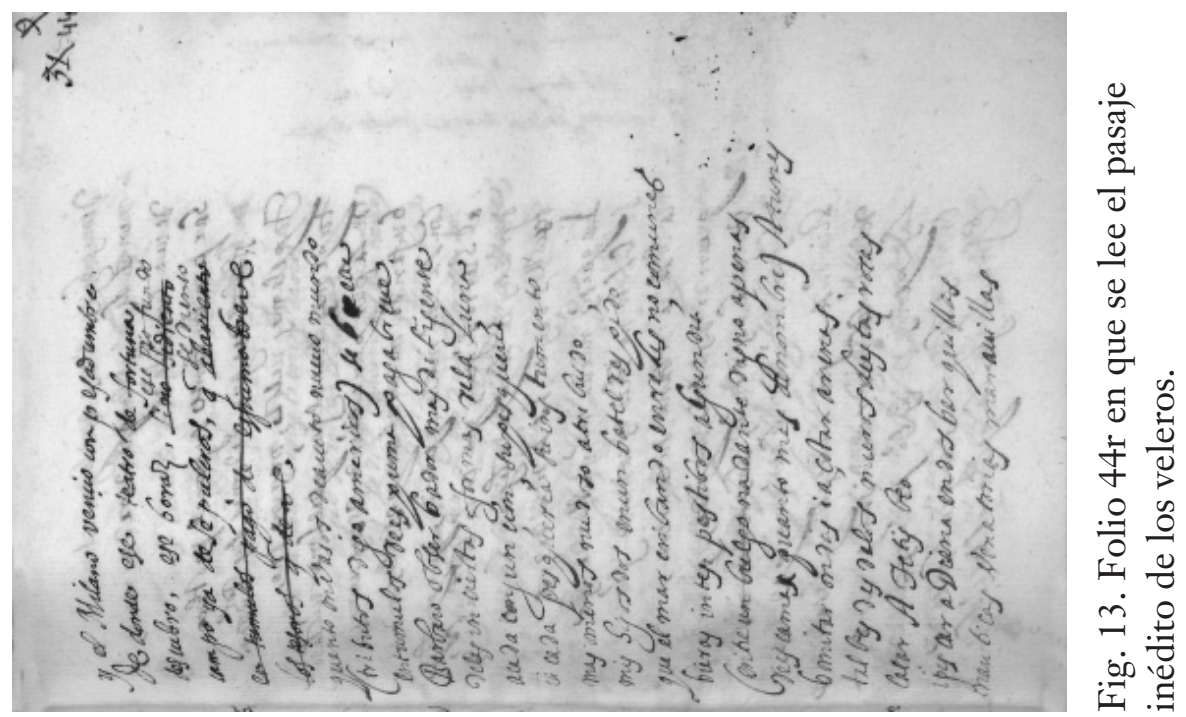

